Special issue of the 3rd International Conference on Computational and Experimental Science and Engineering (ICCESEN 2016)

\title{
Comparative Study of the Adsorption of Methyl Orange by Bentonite and Activated Carbon
}

\author{
A. Bellifa*, M. Makhlouf And Zh. Hechemi Boumila \\ Laboratoire de Matériaux, Applications et Environnement, Faculté des Sciences Exactes, \\ Université Mustapha Stambouli, BP 305, Route de Mamounia, Mascara 29000, Algeria
}

\begin{abstract}
The adsorption of methyl orange dye on activated carbon and bentonite type Algerian clay from aqueous solutions was investigated. The bentonite has been acid-activated, whereas the activated carbon was used without pretreatment. The influence of several parameters (kinetics, contact time, sorbent amount, adsorbate concentration and $\mathrm{pH}$ ) on the adsorption capacity was evaluated and discussed. The methyl orange dye adsorption equilibrium of active carbon is lower than that of bentonite $(3 \mathrm{~h} / 1 \mathrm{~h})$, whereas adsorption yield with active carbon is better than that of bentonite. The adsorption capacity of bentonite is lower than that of active carbon. The methyl orange dye adsorption increases with its concentration in the aqueous solutions. The Frendlich and Langmuir models provided the best fit to the experimental data with high correlation coefficient only for active carbon. The kinetic study demonstrated that methyl orange dye adsorption on bentonite was in a good accordance with the pseudo-secondorder kinetic model. The results showed that bentonite-type clay gave acceptable results compared with activated carbon and is potential to be used as an economical adsorbent for the removal of methyl orange dye.
\end{abstract}

DOI: 10.12693/APhysPolA.132.466

PACS/topics: adsorption, organic dyes, methyl orange

\section{Introduction}

Organic dyes are widely used in industries such as the textile, pulp mill, paper, dye synthesis, food, printing, leather, and plastics industries. Their presence in water in trace amounts is undesirable. Removal of organic dyes from the effluents has become a significant issue in nowadays [1, 2]. Waste effluent containing organic dye endangers not only the environment, but also human life. Various treatment processes for removal dyes from wastewaters, such as ozonation [3], coagulation [4], photocatalytic degradation [5] and adsorption [6, 7] have been widely investigated, during which adsorption is important in both scientific aspects and environmental applications. The adsorption is one of the most effective methods that have been successfully employed for wastes removal $[8,9]$. In this work, methyl orange dye (MO) was selected as model pollutant to investigate adsorption of pollutant onto activated carbon and activated bentonite under different experimental conditions. The bentonite, which is a cheaper and natural material, can also produce similar results to other commercial materials such as activated carbon. The adsorption kinetics of MO on activated carbon and bentonite were studied and different models were applied to fit the experimental data.

\section{Experimentals}

\subsection{Materials}

All chemicals were used without further purification and all solutions were prepared with Milli Q water under

*corresponding author; e-mail: abellifa@yahoo.fr ambient conditions. The bentonite used was in the form of rock from the Maghnia deposit (western Algeria). The bentonite was purified and activated by $\mathrm{HCl}$.

\subsection{Adsorption experiments}

The adsorption experiments were carried out under ambient conditions by using a batch stirred cell. The adsorbate concentrations in the initial and final aqueous solutions were measured by using UV-vis spectrophotometer at $505 \mathrm{~nm}$. The amount of MO adsorbed was calculated from the difference between the initial concentration and the equilibrium one.

\section{Results and discussion}

\subsection{Effect of $p H$, dye concentration and adsorbent mass}

The $\mathrm{pH}$ value of the dye solution plays an important role in the whole adsorption process, especially on the adsorption capacity. Figure 1 shows the effects of $\mathrm{pH}$ on

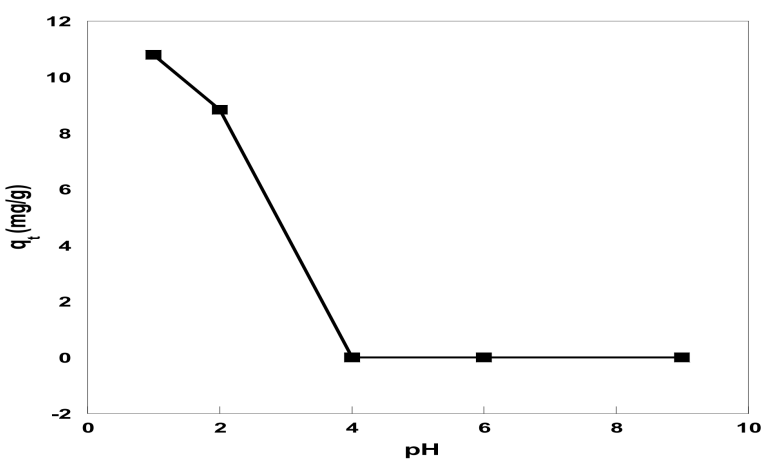

Fig. 1. Effect of $\mathrm{pH}$ on the adsorption of $\mathrm{MO}$ on bentonite. 


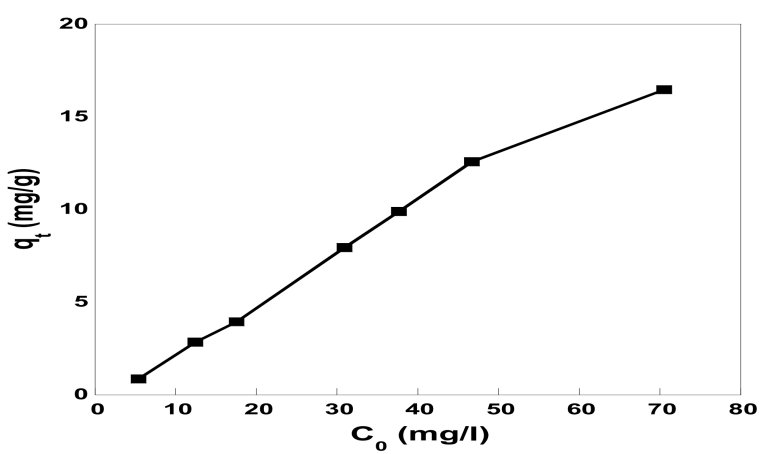

Fig. 2. Effect of concentration on MO adsorption on bentonite.

the adsorption of MO on bentonite. The adsorption of MO decreased sharply in the $\mathrm{pH}$ range of 1.0-4.0 and remained at a constant level for $\mathrm{pH}$ at $4.0-8.0$.

Figure 2 shows the effect of initial concentration on $\mathrm{MO}$ adsorption. It is obvious that the adsorption of MO increases with the dye concentration rising, which suggests that high concentrations of MO favor to the formation of precipitate on the bentonite surface due to the limited solubility of MO. The mass effect on MO adsorption has also been studied. The results showed that the mass of activated carbon does not affect the amount adsorbed.

\subsection{Effect of shaking time}

The adsorption of MO on bentonite is quite quick and the adsorption equilibrium is achieved in less than $60 \mathrm{~min}$ as shown in Fig. 3. On the other hand, equilibrium time of MO adsorption is about $180 \mathrm{~min}$ with yield around $96 \%$.

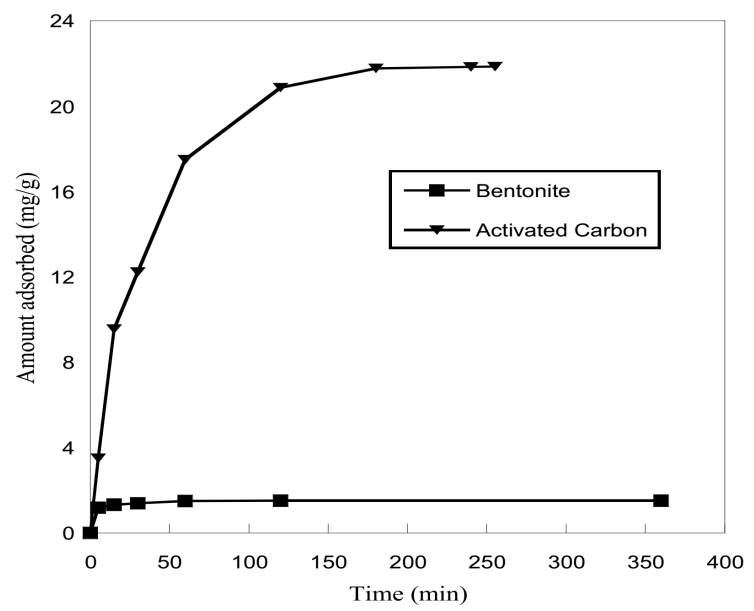

Fig. 3. Effect of shaking time on the adsorption of MO.

\subsection{Isotherm and adsorption kinetic}

In view of Fig. 4, we find that the adsorbed amount increases as a function of the increase equilibrium concentration. These results indicate that both activated carbon and bentonite are very good adsorbents for MO at room temperature. The experimental data of MO adsorption were analysed with the Langmuir and Freundlich isotherm models with the relative values calculated from the two models in Tables I and II. It can be concluded that both Langmuir and Frendlich model coincide with the experimental data for activated carbon. In the case of bentonite, both models (Langmuir and Frendlich) describe the adsorption isotherm only for three points.

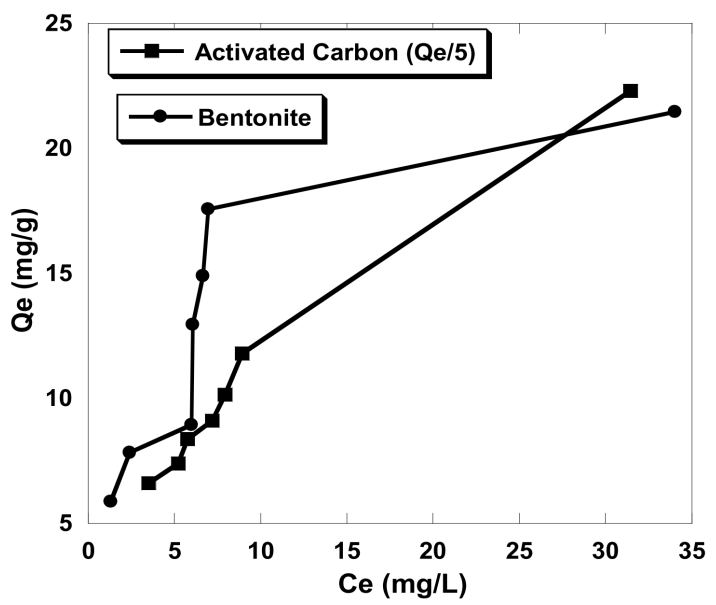

Fig. 4. Adsorption isotherms of MO on activated carbon and on bentonite.

Constants of the Langmuir model.

TABLE I

\begin{tabular}{c|c|c|c}
\hline \hline Adsorbent & $Q_{m}[\mathrm{mg} / \mathrm{g}]$ & $b[\mathrm{~L} / \mathrm{mg}]$ & $R^{2}$ \\
\hline activated carbon (AC) & 200 & 0.048 & 0.967 \\
bentonite (only three points) & 118 & 0.0082 & 0.99
\end{tabular}

Constants of the Frendlich model.

TABLE II

\begin{tabular}{c|c|c|c}
\hline \hline Adsorbent & $K[\mathrm{~L} / \mathrm{g}]$ & $n$ & $R^{2}$ \\
\hline activated carbon & 15.30 & 0.578 & 0.982 \\
bentonite (only three points) & 0.85 & 0.93 & 0.99
\end{tabular}

Fitting of kinetic data to pseudo-second order kinetic model was shown in Fig. 5. The best fit of the pseudosecond order kinetic model $\left(R^{2}=1\right)$ in the present system shows the adsorption of dye followed by chemisorption mechanism via electrostatic attraction.

TABLE III

Thermodynamic data for adsorption of MO on bentonite.

\begin{tabular}{|c|c|c|c|c|c|c|c|}
\hline \multicolumn{2}{|c|}{\begin{tabular}{|c|c}
$\Delta H^{\circ}$ & $\Delta S^{\circ}$ \\
{$\left[\mathrm{kJ} \mathrm{mol}^{-1}\right]$}
\end{tabular}} & $R^{2}$ & \multicolumn{5}{|c|}{$\begin{array}{c}-\Delta G^{\circ}\left[\mathrm{kJ} \mathrm{mol}^{-1}\right] \\
(T[\mathrm{~K}])\end{array}$} \\
\hline 5.28 & 0.0189 & 0.99 & 0.15 & 0.404 & 0.574 & 0.725 & 0 \\
\hline & & & $(288)$ & (301) & $(310)$ & $(318)$ & $(328)$ \\
\hline
\end{tabular}

Values of thermodynamic parameters are listed in Table III. The positive value of $\Delta H$ showed that the adsorption process of the MO on bentonite was endothermic. However, the negative value $\Delta G$ decreased with an increase in temperature, indicating spontaneity of the adsorption process for the adsorbent. 


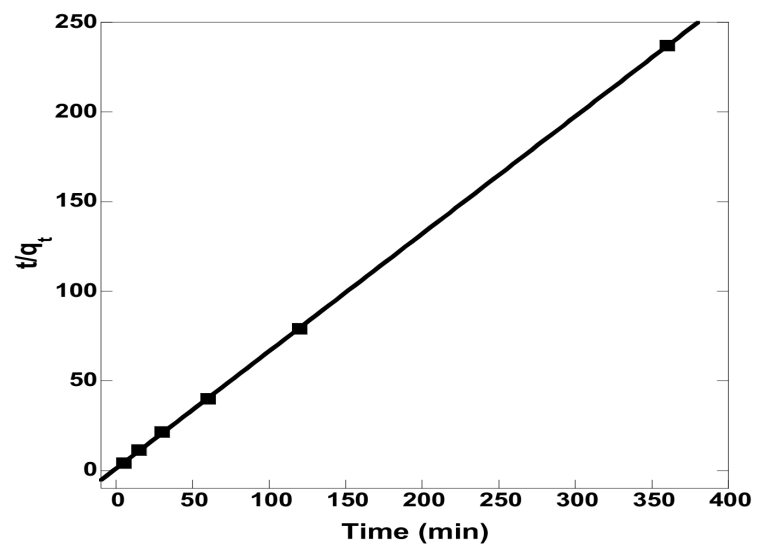

Fig. 5. Fitting of kinetic data to pseudo-second order kinetic model (bentonite).

\section{Conclusion}

Bentonite and activated carbon are excellent adsorbents for MO adsorption. Good yields were obtained with the two adsorbents. The adsorption isotherm is type II as "S" with formation of a monolayer followed by multilayer. Negative values of free energy $\Delta G$ indicated spontaneity of the adsorption of MO. This study showed that the adsorption results are almost similar with a slight advantage for activated carbon. These results are promising and bentonite has proved to be an excellent adsorbent for MO.

\section{References}

[1] H. Han, W. Wei, Z. Jiang, J. Lu, J. Zhu, J. Xie, Coll. Surf. A Physicochem. Eng. Asp. 509, 539 (2016).

[2] Y. Qi, M. Yang, W. Xu, S. He, Y. Men, J. Coll. Interface Sci. 486, 84 (2016).

[3] J. Basiri Parsa, S. Hagh Negahdar, Separat. Purific. Technol. 98, 315 (2012).

[4] I. Khouni, B. Marrot, P. Moulin, R. Ben Amar, Desalination 268, 27 (2011).

[5] F. Xia, E.C. Ou, L. Wang, J.Q. Wang, Dyes Pigm. 76, 76 (2008).

[6] D.S. Sun, X.D. Zhang, Y.D. Wu, X. Liu, J. Hazard. Mater. 181, 335 (2010).

[7] P. Bradder, S.K. Ling, S.B. Wang, S.M. Liu, J. Chem. Eng. Data 56, 138 (2011).

[8] K. Lament, P. Mazur, S. Zuber, A. Ciszewski, Acta Phys. Pol. A 124, 775 (2013).

[9] J. Srenscek-Nazzal, U. Narkiewicz, A. Morawski, R. Wrobel, A. Gesikiewicz-Puchalska, B. Michalkiewicz, Acta Phys. Pol. A 129, 394 (2016). 